\title{
Origen, evolución y pervivencia de las comunidades de villa y tierra: la comunidad abulense como ejemplo
}

\author{
M. ${ }^{a}$ Ángeles Montoya tamayo
}

El deseo, las circunstancias, el peligro, el temor o el simple afán de supervivencia, son algunas de las causas que han dado lugar a vocablos tales como Merindad, Comunidad, Universidad, Asocio, Mancomunidad, etcétera. Terminología que, lejos de difuminarse en la opulencia del lenguaje, transciende a la realidad cotidiana que preside la evolución de la Historia, en forma de Instituciones. A excepción de la primera, el resto de expresiones citadas pertenecen a un tronco común; es más, se puede afirmar que todas son titulares de la misma idea que las engendró, sólo que con la transformación propia del tiempo han participado de los cambios del lenguaje, todo ello envuelto, en ocasiones, con el celofán de las leyes vigentes.

Los términos Comunidad y Merindad, si bien difieren entre sí, ambos arrancan de la época altomedieval, y, en concreto, de la repoblación que tuvo lugar desde las montañas cantábricas hasta el Tajo. Comunidad y Merindad son dos modelos distintos de organización administrativa utilizados en esta repoblación.

Existen limites geográficos y cronológicos entre ambos modelos. Así se puede decir que, desde Tordesillas hasta Aranda, el rio Duero constituye la frontera geográfica, es decir, al norte de este rio, hay que hablar de Merindades $y$, al sur, de Comunidades de Villa y Tierra. Pero existe una excepción, las tierras de Curiel y Roa que, aunque se ubican al norte del río, pertenecen a las Comunidades. A partir de Aranda el Duero ya no es el eje divisorio, de ahí que no sorprenda el hecho de que por el 
norte del río la mayor parte de la hoy provincia de Soria se encuentre distribuida en Comunidades de Villa y Tierra.

Por lo que se refiere a la frontera cronológica, ésta se ve determinada por un hecho histórico: las expediciones de Almanzor. Por eso, al hablar de Merindades hay que señalar las viejas tierras cristianas del siglo VIII con las repoblaciones de los siglos IX y $\mathrm{x}$. Las Comunidades agrupan el nuevo territorio recuperado o ganado durante los siglos XI y XII.

Además de estas diferencias geográficas y cronológicas, existen las propias de dos modelos distintos de organización administrativa. En las Merindades, el sistema político-administrativo estaba formado por el Rey, que tenía todos los poderes políticos, judiciales y militares; los condes, que gobernaban diversas comarcas del reino; los jueces o sayones, que estaban al cargo de los alfoces o suburbios; dentro de los alfoces hay que hablar de aldeas, es decir, centros de población local que tenian su término y su Concejo. Pero la organización de condados desaparece en el siglo XI y en su lugar aparecen los tenentes, que estarán al frente de uno o varios alfoces. El cargo de tenente pronto fue sustituido por el de merino del Rey. Esto por lo que respecta al modelo político-administrativo ubicado al norte del río Duero, pero, al sur del río, el modelo empleado fue distinto. En vez de condados, alfoces y aldeas, hay que hablar de Comunidades de Villa y Tierra. El eje de este sistema fue la Villa, centro de población con aspiraciones urbanas, que solia tener fortaleza y muralla en torno a toda la población. Los vecinos de la Villa se organizaban en Concejo y recibian del Rey una amplia extensión de tierras; sobre este territorio ejercian los derechos de propiedad. El concejo estaba a cargo del nacimiento de las aldeas de su tierra, repartía heredades entre los vecinos, destinaba tierras para aprovechamiento comunal y concejil, daba normas jurídicas para la relación de la Villa con las aldeas, etc. Al conjunto de la Villa y de sus aldeas se le denominaba Comunidad de Villa y Tierra. Los Concejos de las Villa únicamente dependian del Rey ${ }^{\text {. }}$

Una vez vista la diferencia entre los vocablos Merindad y Comunidad, y con ella el origen de ambos, conviene abandonar el primero para centrarse en el segundo y así poder analizar la sucesión de otros términos que han ido surgiendo. Porque hablar de Comunidad, Universidad, Asocio y Mancomunidad, en definitiva es referirse a la estela de cambios que la Historia ha dejado y que unas veces han afectado a Instituciones

Para un desarrollo más amplio véase, MARTinez DIEZ, Gonzalo, Las Comunidades de Villa y Tierra de la Extremadura Castellana. Madrid, 1983. 
ya constituidas, y otras han influido en la denominación de Instituciones de nueva creación. Así, cuando se trata de un nacimiento y no de la simple evolución de una Institución, y si entre las causas se encuentra alguna de las señaladas al inicio del texto -el deseo, las circunstancias, el peligro, el temor o el simple afán de supervivencia-, el nombre que adoptan para ser identificadas suele ser alguno de los últimos que han aparecido. Para clarificar estas afirmaciones sirvan estos datos. El término Universidad se remonta a las fuentes romanas, expresando «la persona colectiva o jurídica, como una entidad claramente definida, con personalidad propia y distinta de la de los diferentes miembros que la integran". Este término se difundió con la recepción romanista de la Edad Media, y, a partir del siglo XII, se aplicó en Cataluña a diversos tipos de corporaciones, siendo la aplicación más generalizada para designar «las comunidades de habitantes de ciudades y villas, en tanto constituían una persona jurídica, aún con anterioridad a la posesión de unos órganos municipales de carácter permanente". Aunque con menor difusión, también adquirió carta de naturaleza en Aragón y Castilla ${ }^{2}$.

Otro de los términos contemplados es el de Asocio. Su origen data de la Ley Municipal de 1870 , en la que se dice que los Municipios se pueden asociar. Por lo que se refiere al término Mancomunidad, ya aparece en la citada Ley y también en la de 1877, pero su procedencia más clara viene del Estatuto del Calvo Sotelo, aprobado el 8 de marzo de 1924, que en su Capítulo II, artículo 6 dice, entre otras cosas, que "los Municipios podrán mancomunarse libremente, aunque pertenezcan a Provincias o Regiones distintas" ${ }^{3}$.

Las Instituciones ya creadas, han pasado por la práctica totalidad de los términos aqui citados. Algunas de ellas, lejos de ir sustituyendo uno por otro, los han ido acumulando, como queriendo aferrarse a lo que ha sido su propia historia; un ejemplo claro lo constituye la Comunidad abulense, que en la actualidad se denomina Mancomunidad Municipal Asocio de la Extinguida Universidad y Tierra de Ávila.

Las Comunidades de Villa y Tierra, inicialmente tuvieron una finaildad común, la defensa de sus tierras y de aquellas otras que iban reconquistando a los musulmanes. Pero una vez pasado el peligro, la finalidad fue el aprovechamiento comunal de montes, pastos, tierras de labor en-

2 Bleiberg, Germán, Diccionario de Historia de España, vol. 3. Madrid, 1981.

3 Tratado en Montoya Tamayo, M. Angeles, Memoria de Licenciatura: Mancomunidad Municipal Asocio de la Extinguida Universidad y Tierra de Ávila en el reinado de Alfonso XIII. 
clavadas en su territorio, etc. Estas Instituciones han ido evolucionando a medida que la Historia ha transcurrido, y así, primero fueron testigos de su enorme poder y del abuso que sus administradores, los denominados Procuradores Generales de la Tierra, cometieron. Luego, asistieron a la caída de ese poder a raiz de la formación de lo que conocemos como Estado Moderno, y, como consecuencia, a una serie de cambios internos que en unos casos les hizo desaparecer, y en otros evolucionar ostensiblemente.

La Comunidad abulense se encuadra dentro de este último caso. De 1849 a 1919 vivió tres formas distintas de administración. El año 1849 supuso un cambio importante dentro de la Institución, ya que se suprimieron los Procuradores Generales que la Comunidad tenia, haciéndose cargo de la inmediata inspección en la administración de los bienes, el Gobernador Civil de la Provincia. Su labor se vio reforzada a partir de 1854 con el nombramiento de un Administrador y de un Depositario. El Gobernador Civil tenía, además, el cargo de Ordenador de Pagos.

Avanzando en el tiempo llegamos a 1824, año en que se creó el cargo de Interventor del Asocio, que recayó en un Concejal del Ayuntamiento de Ávila. En esta nueva forma de administración a cargo del Estado, el Gobernador Civil era el auténtico artifice, el principal protagonista de las decisiones que hubiera que tomar dentro de la Institución, lo que producía, con bastante frecuencia, airadas protestas, sobre todo del Interventor.

En 1911, fruto de conflictos internos dentro de la Entidad que serian largos de detallar en estas líneas, la Comunidad abulense vivió una nueva forma de administración, que vino dada por la RO de 6 de junio de ese año. En ella se dispuso que el Asocio de la Extinguida Universidad y Tierra de Ávila, fuera regido por un Consejo de Administración formado por el Gobernador Civil de la Provincia como Presidente, y del que debian ser vocales el Presidente de la Diputación Provincial, el Alcalde de la Capital, el Comisario Regio de Fomento, el Jefe del Distrito forestal de la Provincia y un representante por todos los demás pueblos que constituian el Asocio, por designación que tenian que hacer sus respectivos Ayuntamientos. Esta etapa, que estuvo comprendida entre 1911 y 1919, fue la transición entre la anterior y la siguiente. Ya no se trataba de una administración a cargo solamente del Estado, empezaba a estar compartida con los propios pueblos miembros del Asocio a través de su representante en el Consejo.

Por RO de 20 de junio de 1919 la Comunidad abulense volvió a recuperar aquella forma de administración perdida en 1849; la citada $R O$ 
concedia la administración a los Municipios que la formaban. La fecha de 20 de junio de 1919 significó para el Asocio la configuración de la forma de administración que iba a regir incluso en nuestro días. Pero, ya no se habló de Procuradores de la Tierra. El artículo 2 del Reglamento dice asi:

"La Junta se compondrá de dos delegados nombrados por cada uno de los cinco grupos o lotes en que se consideran divididos los bienes que integran la Mancomunidad" ${ }^{4}$.

Existen diversos testimonios contrarios a este tipo de Instituciones. Por lo que se refiere a la Comunidad abulense, los más significativos quizá procedan de la información oral y escrita practicada por la Comisión de Reformas Sociales en dicha Provincia, que fue publicada en 1892. En ella, el informante se muestra contrario a los bienes comunales en general, para ello hace un alegato manifiesto en contra de su existencia, basándose principalmente en la falta de justicia social, ya que, según él, estos bienes benefician a los ricos y perjudican a los pobres:

"¿Qué aprovecha el pobre de esa mancomunidad? Alguna miserable carga de leña o lanzar a los prados algún hambriento borriquillo, que fácilmente puede conocerse entre las caballerias de los demás vecinos. El rico, el cacique del pueblo es quien se aprovecha de los mejores árboles, y utiliza la mayor porción de los pastos con sus crecidas ganaderías".

$Y$ añade:

"Como casi siempre estos bienes comunes o concejiles suelen convertirse en bienes propios, es decir, que pasan del aprovechamiento común a quedarse en un recurso del Ayuntamiento para levantar sus habituales cargas municipales, resulta en definitiva un privilegio en favor

${ }^{4}$ Los lotes se constituyeron el 8 de diciembre de 1916, en la reunión que tuvo lugar en el Salón de Sesiones del Palacio Consistorial de la ciudad de Ávila, bajo la presidencia de Alcalde D. Cesáreo Nieto Hernández de Lorenzo.

El citado Reglamento fue aprobado definitivamente y por unanimidad, en la Asamblea General celebrada por los representantes de los pueblos de la Mancomunidad reunidos en Ávila, el 22 de marzo de 1920. 
de un pueblo, a quien el Estado da los medios materiales y especiales de levantar las cargas que por otro lado le impone ${ }^{5}$.

Por lo que respecta a la gran masa de bienes comunales que existen en la provincia, denominados en la época en que se produce esta información, bienes del Asocio de la Universidad y Tierra de Ávila, el informante opina de forma similar, apoyando sus argumentos en otras razones complementarias a las ya expuestas anteriormente:

“... por la existencia ilegal de estos bienes en la forma en que se vienen disfrutando. Bastaria ver las Reales Ordenes de 28 de marzo de 1864 y 3 de abril de 1866, expedidas por el Ministerior de la Gobernación, en las que se declaró por primera vez disuelta dicha universidad, y se mandó que la Hacienda se incautara de los bienes que la componen para proceder a su venta. $Y$ a mayor abundamiento el falio del Tribunal Supremo en 31 de marzo de 1873, en el que no sólo se niega la existencia legal a este Asocio, sino que se llama muy especialmente la atención sobre la falta de cumplimientos de lo mandado, falta que se imputa principalmente a las autoridades que desde 1849 han venido estando encargadas de la inspección, intervención y administración de estos bienes".

Hace especial mención a su mala administración y a los abusos cometidos, de ahi

“... la urgentísima necesidad de la colonización o venta de estos bienes, a fin de que salgan del estado actual».

La mala administración, según opina el informante, ha dado lugar a que

«... de público se diga que las hemosas dehesas que constituyen el Asocio han sido cercenadas y mermadas por los pueblos fronterizos, que borrando antiguos linderos han incluido grandes porciones de ellas 252

5 Reformas Sociales, Información oral y escrita, tomo IV. Madrid, 1985, págs. 250 y 
dentro de sus términos municipales; que su abandono y negligencia ha dado lugar a usurpaciones antiguas y recientes...".

También apunta el hecho de que aunque la administración mejorase, ello no es una razón que se pueda aceptar

«... porque estos bienes no pueden tener nunca una administración conveniente. La única posible hoy por la Ley Municipal seria la de tantos representantes como pueblos son los interesados en el Asocio; y isería racional pensar que una asamblea de 144 individuos (número que se corresponde al número de Municipios que fomaban en esos años el Asocio) pudiera ofrecer seguridad de una administración celosa y acertada? ¿Sería posible suponer que con 144 amos para disponer y mandar, desaparecerían las inmoralidades y abusos que ahora se denuncian? Racionalmente pensando esto no es posible, ni cabe por lo mismo otra solución que la venta de esos terrenos, o mejor aún, su colonización en la parte que se pudiera" ${ }^{6}$.

Con todo ello, el informante ha querido demostrar la opinión, a su juicio generalizada en la época, de que los bienes comunales no deberian de existir porque en lugar de ventajas traen inconvenientes:

«... los bienes comunales no tienen razón de existir bajo el punto de vista de la equidad, por lo imperfectos que tienen que ser sus sistemas de aprovechamiento común; que no convienen tampoco a la prosperidad de la nación, por lo poco o nada que producen, y por lo mucho que impiden el desarrollo de la utilidad imponible; y por último, que su administración no se hace, ni puede hacerse, con arreglo a buenos principios económicos, de modo que si no reúnen condición ninguna ventajosa, y sí males, ¿qué razón seria queda para que subsistan?»?

Las leyes desamortizadoras y la legislación local de la primera mitad del siglo XIX, en cierta forma se adelantaron al sentir de este informante, ya que hicieron muy dificil la supervivencia de este tipo de Instituciones, de ahí que muchas de ellas desaparecieran en esta época y otras se salvaran, no sin importantes cambios estructurales, como ocurrió con la

- Ibidem, págs. 253 y 254.

7 Ibidem, págs. 254 y 255. 
Comunidad abulense. Algunas de ellas aún subsisten en la actualidad, haciendo pervivir con ellas el sentimiento de unión, y sirviendo de ejemplo en la complejidad de la moderna vida local para la formación de nuevas uniones municipales. Las uniones municipales no son un hecho aislado de España, también se dan en Bélgica, Italia, Francia, Rumanía, Alemania, Gran Bretaña, etc., aunque son identificadas con distintos nombres.

En la actualidad, en todos los países existe cierto rechazo por parte de los Municipios a unirse entre sí. En España, es muy reducido el número de asociaciones municipales, Luis Marqués atribuye este hecho:

«... de un lado al acentuado individualismo, la persistente indiferencia ante todo cuanto suponga rotura de viejos moldes, el apego a la rutina, la apatía para obrar diligentemente, han provocado más de una vez el aborto de las mancomunidades de pequeños Municipios, y de otro lado, rivalidades, resquemores avivados, pugnas personales y rencillas perennes entre los pueblos han frustrado, también, muchas convenientes uniones de Municipios" ${ }^{8}$.

Los más destacados tratadistas del Derecho Municipal, coinciden en señalar la conveniencia de la existencia de Mancomunidades para superar las dificultades de los Municipios. Asi se ahorran gastos de personal y se sostienen y mejoran ciertos servicios que pueden ser aprovechados por varios pueblos. Esto es importante, y me atrevería a decir que vital para núcleos reducidos de población, con objeto de remediar sus innumerables insuficiencias. Además, la cooperación intermunicipal hace realidad en los pequeños Municipios, comodidades de las grandes urbes que sin este esfuerzo común se agitarian sin vías de realización en la plenitud de la utopía.

Luis Marqués, habla de Mancomunidades voluntarias y de Agrupaciones municipales forzosas. Entre las primeras se barajan motivos muy diversos, prueba de ello son los ejemplos que cita:

"La Mancomunidad de los Ayuntamientos de Pineda y Tordera (Barcelona), para conservación, mejora y sostenimiento del camino de

${ }^{8}$ Marques Carbo, Luis, "De las Mancomunidades voluntarias y de las Agrupaciones municipales forzosas", Revista de Estudios de la Vida Local, núm. 61, 1952, pág. 42. 
Puente de Pineda a Orsavinyá; la Mancomunidad de los Ayuntamientos de Maracena, Pulianillas y Jun, con inclusión de la Diputación Provincial de Granada, para abastecimiento de aguas; la Mancomunidad de los Ayuntamientos de Alicante, San Juan de Alicante, Muchamiel y otros para el sostenimiento del servicio de incendios; la Mancomunidad denominada "Entror", integrada por los Ayuntamientos de Enfesta, Trazo y Arosa (Coruña), para la construcción y sostenimiento de una casa cuartel para la Guardia Civil; la Mancomunidad de los Ayuntamientos de Usúrbil, Orio y Aya (Guipúzcoa), para la municipalización de suministro de energía eléctrica; la Mancomunidad de los Ayuntamientos de Medina del Campo, Rueda, Tordesillas, Benavente y otros (Valladolid y Zamora), para la construcción y explotación del ferrocarril de Medina a Benavente; la Mancomunidad de los Ayuntamientos de Olot, Vall de Vianya y Begudá (Gerona), para la creación y sostenimiento de Escuela Nacional de Primera Enseñanza; la Mancomunidad de los Ayuntamientos de Almazán, Matamala y Tardelcuende (Soria), a los efectos de tener un ingeniero y un ayudante de Montes comunes, etc." ${ }^{9}$.

Estos ejemplos no se contradicen con la afirmación anteriormente vertida de que existe cierto rechazo, tanto en España como en otros paises, hacia el asociacionismo, porque no hay que olvidar que los casos aquí citados, aunque parezcan numerosos, afectan a un pequeñísimo número de Municipios en proporción a la cifra total que existe en España.

Todas las Mancomunidades citadas tienen una característica común, la voluntad de todos los Municipios que las integran orientada hacia principios de cooperación, solidaridad y auxilio mutuo. Pero existen otras Agrupaciones que son obligatorias, que al contrario que las anteriores, que tienen sus precedentes legislativos en las ya mencionadas Leyes Municipales de 1870 y 1877 , y en el Estatuto de Calvo Sotelo de 1924, sus primeros antecedentes legales hay que ubicarlos, según refiere Luis Marqués:

«... en unos preceptos de la Instrucción de Sanidad del año 1904 sobre prestación de servicios facultativos y sanitarios en los pueblos de pequeña población y reducido presupuesto, y en unas disposiciones de los años 1921 y 1922, dirigidas a organizar y sostener las brigadas sanitarias provinciales. El Estatuto Municipal, en sus artículos 12 a 15, 111,207 y 226, y el Reglamento de población y términos municipales de 2 de julio de 1924, en sus artículos 13 al 15 y 41 , introdujeron de

\footnotetext{
9 Ibidem, págs. 44 y 45 .
} 
manera expresa en nuestro derecho público las agrupaciones municipales obligatorias" ${ }^{10}$.

Como se puede ver, la idea de unión de Municipios para fines comunes, bien sea de forma voluntaria o forzosa, ha sido una realidad en todas las épocas. Pero, en ocasiones, dentro de estas Mancomunidades - Agrupaciones se ha producido y de hecho se sigue produciendo, a su vez, lo que se conoce legalmente como fusión de Municipios que, en ocasiones, conecta con ciertos matices que presenta la opinión pública que permite conocer la complejidad del hecho, los condicionamientos que en cada momento le afectan y sus conexiones naturales con otros problemas sociales. Sin ánimo de entrar en cuestiones tales como si carece o no de sentido toda toda política de fusión o incorporación de Municipios que no tenga en cuenta la transformación de estructuras económicas programadas por el Estado para la zona en que se intente realizar; o bien plantearnos interrogantes como ¿cuáles pueden ser, en términos generales, las líneas de estas transformaciones económicas en las áreas en que actualmente existe exceso de Municipio?, voy a centrarme en un planteamiento mucho más sencillo, pues no alcanza en su totalidad las cotas de análisis, revisión o reorientación de las estructuras institucionales que sería exigible en las dos cuestiones anteriormente citadas. El hecho que voy a exponer, si bien repercutió en los cimientos que sostienen el peso de la Institución en la que se produjo, permitió cuestionar en su día dicho caso con una visión más participativa de los propios miembros implicados, entremezclándose los derechos y los intereses de la Institución y de los Municipios afectados.

El planteamiento se enmarca en la Comunidad abulense, en el año 1977. El hecho deriva una práctica que viene desarrollándose en la Entidad, al menos que se tenga constancia de ello, desde la aprobación por el Supremo Consejo de Castilla, en 10 de mayo de 1719, de la Concordia por la que se rige esta Mancomunidad. Práctica contemplada también en las disposiciones del Reglamento del Régimen y Gobierno de la Institución, vigente en el año 1977, que fue aprobado por la Asamblea General de la Mancomunidad en sesión celebrada en 24 de febrero de 1951 y por el Consejo de Ministros en 21 diciembre de ese mismo año, y supletoriamente en lo dispuesto en la Ley de Régimen Local y sus Reglamen-

10 Ibidem, pág. 42. 
Origen, evolución y pervivencia de las comunidades de villa y tierra...

tos (artículo primero del Reglamento de Régimen y Gobierno de esta Entidad).

El artículo cuarto de dicho Reglamento establece que, a los efectos económicos, de acuerdo con la Concordia citada, corresponde, tanto en bienes, derechos, acciones y explotaciones industriales, presentes y que se puedan establecer, adquirir y reivindicar, la quinta parte al Ayuntamiento de la ciudad de Ávila, y las cuatro quintas partes a los restantes Ayuntamientos y Entidades Locales Menores citadas en el artículo anterior. Esta concordia es la transacción habida entre la ciudad de Ávila y su Tierra, que dio fin al pleito existente entre ambas partes, por el que se sancionó, de común acuerdo - de ahí su hombre de Concordia-, que Ávila tendría derecho a la quinta parte de los bienes o de los beneficios de los mismos de la Entidad, ya que, constituye uno de los cinco grupos o lotes que forman la Mancomunidad, tanto para nombrar representantes, como para percibir los repartos anuales correspondientes. La razón que llevó a los pueblos que integran la Tierra de Ávila a promover pleito contra la ciudad de Ávila, representados por su Procurador General, nombrado por los distintos Sexmeros ${ }^{11}$, fue que no veían motivo justo para que Ávila percibiese la quinta parte de los productos de los bienes del Asocio. Pero la ciudad sostenia que siempre, en toda clase de gastos de la Universidad y Tierra de Ávila, había tenido que soportar los de carácter nacional, bien por visitas de Reyes y Principes nacionales o extranjeros, bien por la celebración de festejos con motivo de triunfos frente a los moriscos. De ahí que considerase justo que le correspondiese la quinta parte de los beneficios. La solución vino como consecuencia de la transigencia entre ambas partes, lo que dió lugar a la citada Concordia.

Una vez expuesto el contexto en el que se enmarca el hecho que va a ser referido, hay que pasar sin más a plantear su contenido y las dimensiones que alcanzó. Tradicionalmente, los repartos antes mencionados se han venido haciendo anualmente, otorgando al Ayuntamiento de Ávila la quinta parte, y las cuatro quintas partes a los restantes Ayuntamientos y Entidades Locales Menores que integran los grupos o lotes segundo, tercero, cuarto y quinto. Pero esto, según el número de habitantes de cada pueblo, es decir, que el grupo o lote segundo, percibe

1 Los sexmeros eran funcionarios municipales que se ponían al frente de cada sexmo. Sexmo entendido --en la época de la Repoblación- como distrito rural formado para el repartimiento de tierras, no teniendo en cuenta la superficie, sino la situación y calidad. Pasada la etapa de la Repoblación el concepto de sexmo evoluciono, de tal modo que, en la mayoria de las ciudades castellanas, pasó a significar el conjunto de aldeas de su término rural, o cada uno de los sectores o distintos en los que se dividia el mismo. 
una cantidad igual mayor o menor que el grupo tercero, y asi sucesivamente, en función de que el número de habitantes de sus pueblos sea igual, mayor o menor. Hasta aquí, todo parece normal, pero el conflicto afloró a raiz de la incorporación, por fusión, al Ayuntamiento de Ávila de los Ayuntamientos de Alamedilla del Berrocal, Aldea del Rey Niño, Narrillos de San Leonardo y Vicolozano, ya que se planteó el problema de si las cantidades que correspondían a esos Ayuntamientos - a partir de la fusión desaparecidos - habia que asignárselas al Ayuntamiento de Ávila, o por el contrario, si habían de primar a favor de los pueblos que integraban los restantes lotes. No voy a entrar a analizar los trámites que se siguieron ni mucho menos los informes que de tal hecho se derivaron, tanto por parte del Servicio de Inspección y Asesoramiento de las Corporaciones Locales, como los provinientes de las propias autoridades de la Mancomunidad, pues sería pesado por el formulismo seguido y por la reiteración que de diversos conceptos, en ocasiones, se hizo. Sólo decir que la solución no fue otra que la de hacer llegar al Ayuntamiento de Ávila la parte que correspondiera en los repartos a sus núcleos incorporados.

Al esbozar este caso, he querido dejar constancia de que el contexto, contenido, desarrollo y solución del problema planteado es un ejemplo de que las Comunidades de Villa y Tierra han tenido un origen y una evolución, y que las que perviven aún hoy, han sabido adaptarse y solucionar o al menos enfrentarse con los problemas que les han acontecido en cada época.

Otro ejemplo en esta línea se dio también durante la Transición, y, en concreto, en el período comprendido entre 1975 y 1982. En él, la Mancomunidad abulense vivió un momento bastante polémico dentro de su historia, pues se suprimieron los cargos de Interventor y de Depositario, todo ello enmarcado dentro de la política seguida por sus autoridades en estos años, de reducir gastos por medio de la amortización de plazas que fueran quedando vacantes. En palabras del Presidente habia que:

«... reducir gastos por amortización de plazas del personal, según se vayan produciendo por jubilación, dejando el número suficiente para una administración eficiente y poder repartir a los pueblos mancomunados cantidades superiores a las actuales" ${ }^{12}$.

12 "Borrador del Acta de la Sesión ordinaria celebrada por la Asamblea General el dia 31 de marzo de 1980", Boletin informativo. Ávila, 9-5-1980, Archivo del Asocio. 
Origen, evolución y pervivencia de las comunidades de villa y tierra...

La opinión del Secretario era similar:

«... debe tenderse a que quede en la misma un Secretario, tres administrativos y un ordenanza, asi como reducir el número de guardas, teniendo en cuenta los actuales caminos de los montes y su cierre por alambradas, que facilita la custodia de los mismos" ${ }^{13}$.

Hecho que se instala a su vez dentro de la tónica de destrucción de empleos que se estaba dando en la provincia, y que ya se venía sintiendo desde 1964. En palabras de D. Isidro Hernández Perlines, Director General de Economía y Planificación de la Junta de Castilla y León (1985), el número de empleos en la provincia de Ávila descendió considerablemente:

«... las cifras de empleo provincial pasaron de 91.579 personas en 1964 a 71.384 en 1973 y 54.638 en 1981 , según datos del Banco de Bilbao. Según los datos de la encliesta de Población Activa (EPA), el ritmo de destrucción de empleos en el periodo 1976-1981 ha sido del 6,16 por 100 anual acumulativo, mientras que la tasa regional correspondiente se situaba en el 4,12 por $100,{ }^{14}$.

Las citadas plazas de Interventor y de Depositario, como tales, no se crearon hasta 1951, debiendo pertenecer el Interventor, al Cuerpo de Interventores de Administración Local, y el Depositario, al Cuerpo Nacional de los Fondos de la Administración Local, y, por lo tanto, percibiendo el sueldo que la ley fijara. Pero, los cargos en si datan de 1854, desempeñando el de Interventor, de 1854 a 1911, un Concejal del Ayuntamiento de Ávila. De 1911 a 1919, el Alcalde del Ayuntamiento de Ávila y de 1919 a 1951 fue nombrado por votación del seno de la Junta. Se trataba pues, de un cargo desempeñado por una persona que a su vez tenía su propia plaza en otro organismo o entidad, percibiendo por ello un sueldo; no asi por desempeñar los cometidos del cargo de interventor, por el que el Ayuntamiento, que no la Mancomunidad, le daba una gratificación en concepto de gastos.

13 Ibídem.

${ }^{14}$ Varios autores: Estructura socioeconómica de la Provincia de Avila. Ávila, 1985, pág. 44 
También data de 1854 el cargo de Depositario, éste era nombrado directamente por el ministro de la Gobernación, no especificándose si la persona en la que recaía desempeñaba ya otro cargo, como ocurrió en el caso del Interventor. Pero, el hecho de no aparecer datos en la documentación consultada sobre el posible sueldo que pudiera percibir, hace pensar que la persona elegida para desempeñarlo, además, tuviera el suyo propio. Este cargo fue suprimido en época del Consejo, 1911-1919, no apareciendo hasta 1951 , esta vez como plaza creada.

La supresión de las plazas de Interventor y de Depositario fue un hecho, y la polémica derivada de esta decisión se zanjó al quedar aprobado el Reglamento reformado ${ }^{15}$.

Para finalizar sirvan estas reflexiones. Las Comunidades de Villa y Tierra merecen ser magnificadas, porque además de pervivir gran número de ellas a través de la Historia, han servido de ejemplo para otras asociaciones $o$ agrupaciones de Municipios que se han formado con posterioridad a ellas. En su labor ejemplar han mantenido el ánimo y el tesón que un día las vio nacer y que desde entonces se convirtió en el emblema que ha presidido la mayor parte de sus actuaciones. Además, estas Comunidades son un rico manantial de historia del que surgen frutos maduros cuyas semillas germinaron gracias a la experiencia acumulada, y al hecho de haber sido agentes activos de las diversas etapas de la realidad vivida. Al permanecer todavia entre nosotros con un palpitar acompasado con las exigencias del tiempo, fácilmente nos pueden reflejar a través de sus archivos, cual baúl que guarda polvoriento indicios de otras épocas, que aún no están ancladas en el recuerdo, porque alli se encuentran documentos antiguos y testimonios modernos en perfecta armonía. Esta conjunción reafirma su origen, evolución y pervivencia entre nosotros, como queriéndonos mostrar su impertérrito y perenne deambular por siglos y siglos de trascendencia asumida.

${ }^{15}$ Este Reglamento habia sido acordado modificar previa facultad conferida por acuerdo de la Asamblea General de 31 de marzo de .1980 , por la Junta de Administración de esta Entidad, en sesión celebrada el 24 de abril de 1980. La Asamblea General celebrada el 12 de diciembre del mismo año, acordó la remisión del expediente administrativo a la Superioridad, la cual aprobó la modificación reglamentaria por Real Decreto 2192/1981 de 20 de agosto, siendo ratificada dicha modificación por la Asamblea General el 11 de diciembre de 1981. Para un desarrollo más amplio véase el Reglamento de Régimen y Gobierno de la Mancomunidad Municipal Asocio de la Extinguida Universidad y Tierra de Avila. Ávila, 16-12-1981, Archivo del Asocio. 